\title{
Synthesis, structural and optical properties of nanoparticles (Al, V) co-doped zinc oxide
}

\author{
J EL GHOUL ${ }^{1,2, *}$ \\ ${ }^{1}$ Al Imam Mohammad Ibn Saud Islamic University (IMSIU), College of Sciences, Department of Physics, Riyadh 11623 , \\ Saudi Arabia \\ ${ }^{2}$ Laboratory of Physics of Materials and Nanomaterials Applied at Environment (LaPhyMNE), Gabes University, Faculty \\ of Sciences in Gabes, Gabès 6072, Tunisia
}

MS received 9 April 2015; accepted 9 October 2015

\begin{abstract}
The synthesis by the sol-gel method, structural and optical properties of $\mathrm{ZnO} \mathrm{Zn}_{0.99} \mathrm{Al}_{0.01} \mathrm{O}(\mathrm{AlZ}$ ), $\mathrm{Zn}_{0.9} \mathrm{~V}_{0.1} \mathrm{O}(\mathrm{VZ})$ and $\mathrm{Zn}_{0.89} \mathrm{Al}_{0.01} \mathrm{~V}_{0.1} \mathrm{O}$ (AIVZ) nanoparticles was reported. The approach was slow release of water for hydrolysis by esterification reaction followed by a supercritical drying in ethyl alcohol. After thermal treatment at $500^{\circ} \mathrm{C}$ in air, the obtained nanopowders were characterized by various techniques such as transmission electron microscopy, X-ray diffraction and photoluminescence (PL) spectroscopy. The structural properties showed that the $\mathrm{ZnO}$ nanoparticles with an average particle size of $25 \mathrm{~nm}$ exhibit hexagonal wurtzite structure. From the optical studies, it was found that the optical band gap was located between 2.97 and 3.17 eV. The obtained electrical properties showed the potential application of the samples in optoelectronic devices. The powder of AIVZ presented a strong luminescence band in the visible range. The PL band energy position presented a small blue shift with the increase of measurement temperature. Different possible attributions of this emission band will be discussed.
\end{abstract}

Keywords. Sol-gel process; (Al, V) co-doped $\mathrm{ZnO}$ nanoparticles; optoelectronic properties; luminescence.

\section{Introduction}

Doping semiconductor nanostructures in order to control their physical properties is an active field of research related to the development of nanotechnology applications [1-3]. Owing to the variety of $\mathrm{ZnO}$ applications, nanowires and other nanostructures of this semiconducting oxide have been doped with different metal ions, including transition metal elements (Ni, Fe, Mn, Co, V, etc.) [4-9]. ZnO photoluminescence (PL) has been studied for several decades. Most of the studies represent the PL spectra of $\mathrm{ZnO}$ consisting of a sharp exciton related UV luminescence and a defect-related visible emission. The defect-related emissions are located in a wide range of the visible spectrum, such as violet [10], green [11], yellow [12,13] and orange-red [14-16] emissions. Great efforts have been made to modify and tailor the visible emissions of $\mathrm{ZnO}$ by introducing impurities including $\mathrm{Al}, \mathrm{Mg}, \mathrm{Li}$, $\mathrm{V}$, In and trioctylamine/trioctylphosphine oxide [2,17-20]. In recent times, Ohashi et al [21] prepared $\mathrm{Li}$ and $\mathrm{Al}$ co-doped $\mathrm{ZnO}$ (LAZO) powders by mixing $\mathrm{ZnO}$ powder with aqueous solution of $\mathrm{LiCl}$ and $\mathrm{Al}(\mathrm{NO})_{3}$, then drying the mixture and annealing it at $900^{\circ} \mathrm{C}$ in oxygen. They observed yellowishwhite luminescence from the LAZO powders. Nayak et al [22] also reported stable, highly intense and yellowish-white

\footnotetext{
*Author for correspondence (ghoultn@yahoo.fr)
}

luminescence from LAZO nanopowders synthesized via a chemical co-precipitation technique. In most of these studies the synthesis and doping are achieved by a sol-gel process.

$\mathrm{Up}$ to now, doped and co-doped $\mathrm{ZnO}$ multifunctional materials by sol-gel $[3,23,24]$ for magnetic and electric properties was fabricated. Aluminium which introduces a shallow effective mass like donor state doping was used. Its solubility range is in the at\% range but it might be modified by the codoping element. In the present paper, the effect of vanadium and aluminium as co-doping element of $\mathrm{ZnO}$ nanopowder on structural and optoelectronic properties have been reported.

\section{Experimental}

\subsection{Sample preparation}

$\mathrm{Zn}_{0.89} \mathrm{Al}_{0.01} \mathrm{~V}_{0.1} \mathrm{O}$ nanocrystals were prepared by the sol-gel method using $16 \mathrm{~g}$ of zinc acetate dehydrate as precursor in a $112 \mathrm{ml}$ of methanol. After $10 \mathrm{~min}$ magnetic stirring at room temperature, $0.628 \mathrm{~g}$ of ammonium metavanadate corresponding to $[\mathrm{V}] /[\mathrm{Zn}]=0.10$ and an adequate quantity of aluminium nitrate-9-hydrate corresponding to $[\mathrm{Al}] /[\mathrm{Zn}]$ ratios of 0.010 were added. After an additional 15 min magnetic stirring, the solution was placed in an autoclave and dried under supercritical conditions of ethyl alcohol (EtOH). The obtained powder was then heated in a furnace at $500^{\circ} \mathrm{C}$ for $2 \mathrm{~h}$ in air. 


\subsection{Characterization techniques}

The crystalline structure and phase purity of the aerogel after thermal treatment were investigated by X-ray diffraction (XRD) using the $\mathrm{CuK} \alpha$ radiation $(\lambda=1.5418 \AA$ ) of a Bruker D5005 diffractometer. The aerogel powders were also characterized using a JEM-200CX transmission electron microscope (TEM). The specimens for TEM were prepared by applying the as-grown products in ethyl alcohol and immersing them in an ultrasonic bath for $15 \mathrm{~min}$, then dropping a few drops of the resulting suspension containing the synthesized materials onto TEM grid. Optical properties were carried out by using an UV-vis-IR spectrophotometer (Shimadzu UV3101 PC spectrophotometer). The four-point probe (SZ-82) was used for the measure of the sheet resistance $\left(R_{\mathrm{S}}\right)$. For PL measurements, the 450 Xenon lamp has been used as an excitation source. The emitted light from the sample, collected by an optical fibre on the same side as the excitation, was analysed with a Jobin-Yvon Spectrometer HR460 and a multichannel CCD detector (2000 pixels). The PLE measurements were performed on Jobin-Yvon Fluorolog 3-2 spectrometer. The emission spectra were corrected for the spectral response of the excitation source. The low temperature experiments were carried out in a Janis VPF-600 Dewar with variable temperature controlled between 78 and $300 \mathrm{~K}$.

\section{Results and discussion}

Figure 1 shows typical XRD spectra of the aerogel powders of all samples. In the case of undoped $\mathrm{ZnO}$, the appearance of nine pronounced diffraction peaks at $2 \theta=31.82^{\circ}, 34.61^{\circ}$, $36.36^{\circ}, 47.55^{\circ}, 56.73^{\circ}, 62.88^{\circ}, 66.34^{\circ}, 68.08^{\circ}$ and $69.19^{\circ}$ was noticed, which can be attributed to the (100), (002), (101), (102) (110), (103), (200), (112) and (201) planes of $\mathrm{ZnO}$, respectively [5]. After doping of $\mathrm{ZnO}$ with vanadium and thermal treatment, in addition to the peaks corresponding to $\mathrm{ZnO}$, four secondary additional phases were

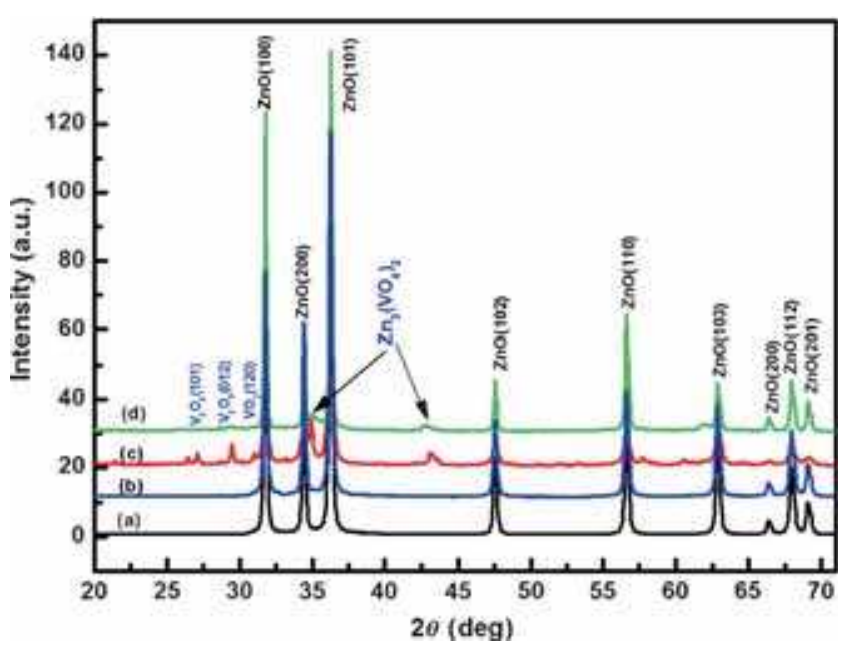

Figure 1. X-ray diffraction spectra of (a) $\mathrm{ZnO}$, (b) $\mathrm{AlZ}$, (c) $\mathrm{VZ}$ and (d) AlVZ nanoparticles. detected which can be attributed to $\mathrm{VO}_{2}$ (120), $\mathrm{V}_{2} \mathrm{O}_{3}(012)$, $\mathrm{V}_{2} \mathrm{O}_{5}$ (101) and $\mathrm{Zn}_{3}\left(\mathrm{VO}_{4}\right)$ in the case of vanadium doping $[4,5]$. By against, the appearance of peaks corresponding to aluminium doping was not noticed. Due to the small size of the crystallites in the aerogel, the diffraction lines are broadened and are further found to depend on the Miller indices of the corresponding sets of crystal planes. The average grain size can be calculated using the Debye-Scherrer equation [25]

$$
G=\frac{0.9 \lambda}{B \cos \theta_{\mathrm{B}}},
$$

where $\lambda$ is the X-ray wavelength $(1.5418 \AA), \theta_{\mathrm{B}}$ the maximum of the Bragg diffraction peak, and $B$ the linewidth at half-maximum. After a correction for the instrumental broadening, an average value of the basal diameter of the cylinder-shape crystallites is found to be $15-22 \mathrm{~nm}$, whereas the height of the crystallites is $22-30 \mathrm{~nm}$. From the symmetric peaks, it was found that the lattice parameter $c$ of AlVZ ( $c=5.191 \AA$ ) is smaller than the value $c$ of undoped $\mathrm{ZnO}$ ( $c=5.210$ ), which is close to the value of conventional nanosized crystallites $\{c$-lattice from crystallographic data: ICSD reference number: 67848-1993 (5.2151 ̊) and 67454-1989 (5.2071 $\AA$ ) $\}$. This reduction in lattice parameter may be due to a diminution in size of the nanoparticles after doping [4].

Figure 2 shows the TEM images of representative particles of all samples as well as the high-resolution TEM (HRTEM) image of $\mathrm{ZnO}$ and energy-dipersive X-ray spectroscopy (EDX) analyse of AlVZ sample. The morphologies of all the samples are found to be nearly spherical in nature with the diameters ranging from 19 to $28 \mathrm{~nm}$. It clearly shows that the average particle size of these samples is nanoscale and it is in accordance with the results of the XRD. The HRTEM image clearly showed that the measured distance between the planes of the fringes is $0.26 \mathrm{~nm}$ (figure $2 \mathrm{a}$ ), which is corresponding to the (002) planes of the wurtzite $\mathrm{ZnO}$. The EDX spectrum showed signals directly related to the dopants. $\mathrm{Zn}$ and $\mathrm{O}$ appeared as the main components with low levels of $\mathrm{V}$ and $\mathrm{Al}$ (figure $2 \mathrm{~d}$ ). This confirmed the formation of $\mathrm{Al}$ and $\mathrm{V}$ co-doped $\mathrm{ZnO}$.

The optical properties of the material are shown in figure 3 . The spectra are characterized by high transmittance in the visible range (figure $3 a$ ) and an intense fundamental absorption due to nanoparticles $\mathrm{ZnO}$ in the spectral range between 300 and $400 \mathrm{~nm}$ (figure 3b). There is a red shift in the absorption edge for AlVZ that can be attributed to the presence of $\mathrm{V}$ and $\mathrm{Al}$ in the $\mathrm{ZnO}$.

The absorption coefficient $\alpha$ is related to the optical energy band gap $E_{\mathrm{g}}$ for high photon energies as [4]

$$
\alpha(h v)=C\left(h v-E_{\mathrm{g}}\right)^{1 / 2},
$$

where $C$ is a constant for direct transition and $h v$ the energy of the incident photon. The plot of $(\alpha h v)^{2}$ against $(h v)$ shows a linear dependence. This means that $\mathrm{ZnO}$ are direct transition-type semiconductor.

Plotting $(\alpha h v)^{2}$ as a function of photon energy and extrapolating the linear portion of the curve to absorption equal to 

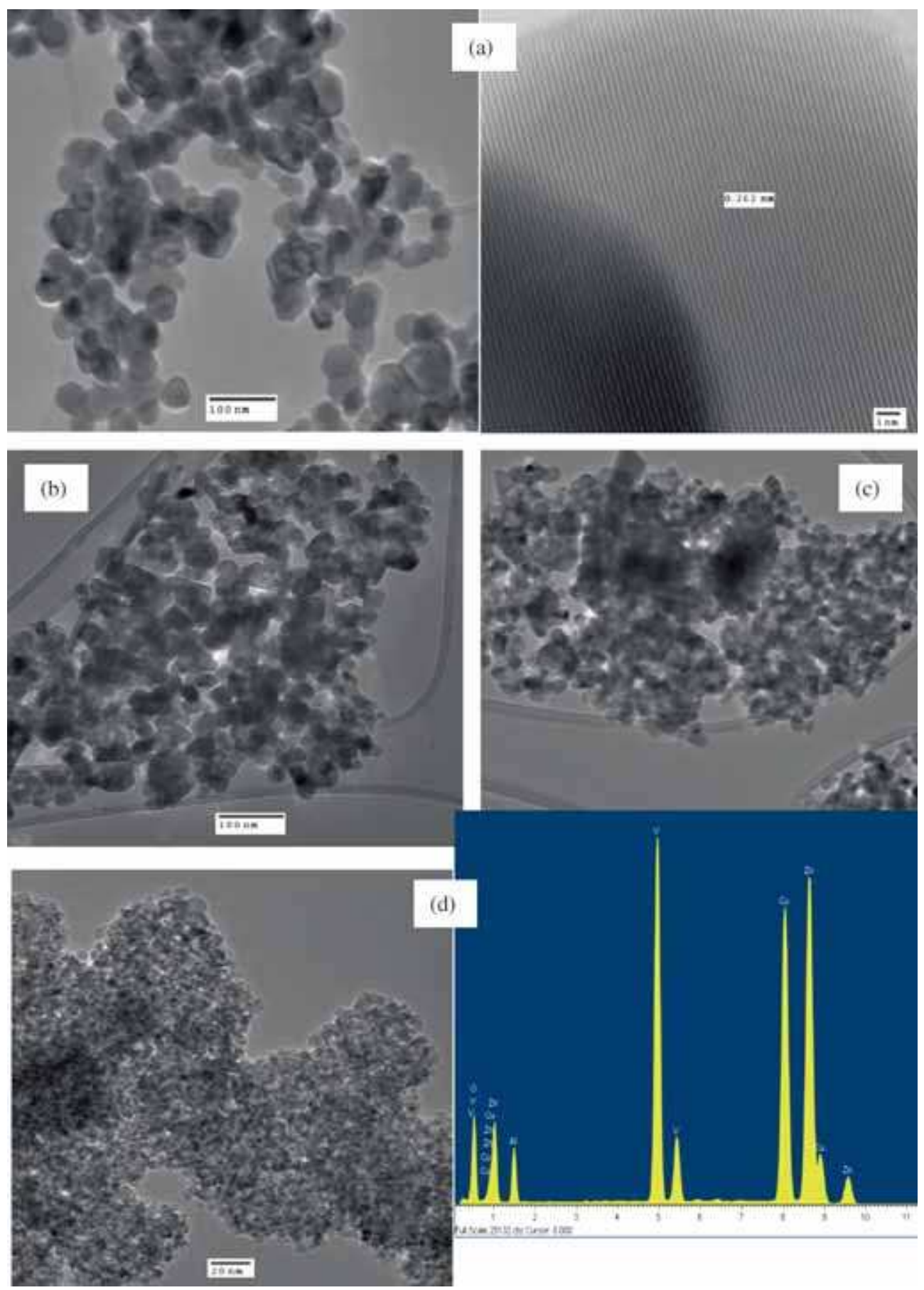

Figure 2. HRTEM images and EDX analysis of (a) $\mathrm{ZnO}$, (b) AlZ, (c) VZ and (d) AlVZ nanoparticles.

zero as shown in figure 4 , gives the values of the direct band gap $\left(E_{\mathrm{g}}\right)$ to be 3.17, 3.09, 3.03 and $2.97 \mathrm{eV}$ for the samples of $\mathrm{ZnO}, \mathrm{VZ}, \mathrm{AlZ}$ and $\mathrm{AlVZ}$, respectively. In the case of Aldoped $\mathrm{ZnO}$, the shift to lower energy due to doping seems to be related to the presence of localized donor levels $\left(E_{\mathrm{e}}\right)$ in the band gap. Based on the presence of VO groups confirmed by XRD, it was expected that the small direct band gap of the $\mathrm{VO}$ groups such as $\mathrm{V}_{2} \mathrm{O}_{5}(2.3 \mathrm{eV})[26,27]$ may be responsible for the decrease of the band gap in the V-doped $\mathrm{ZnO}$ samples.
The sheet resistance $\left(R_{\mathrm{s}}\right)$ of the all samples was measured by the four-point probe method. Table 1 presents the $R_{\mathrm{s}}$, the electrical resistivity $(\rho)$ and the transmittance at $550 \mathrm{~nm}$ of all samples. The average transmittance in the visible region varies between 78 and $89 \%$. The high transmittance and minimal resistivity of $1.26 \times 10^{-3} \Omega \mathrm{cm}$ was obtained for $\mathrm{ZnO}$ sample. The decrease of resistivity can be attributed to the improvement of crystallinity and the increase of grain size [28], which is confirmed by the results of XRD discussed above. The sum of the obtained results for $\mathrm{ZnO}$ and 

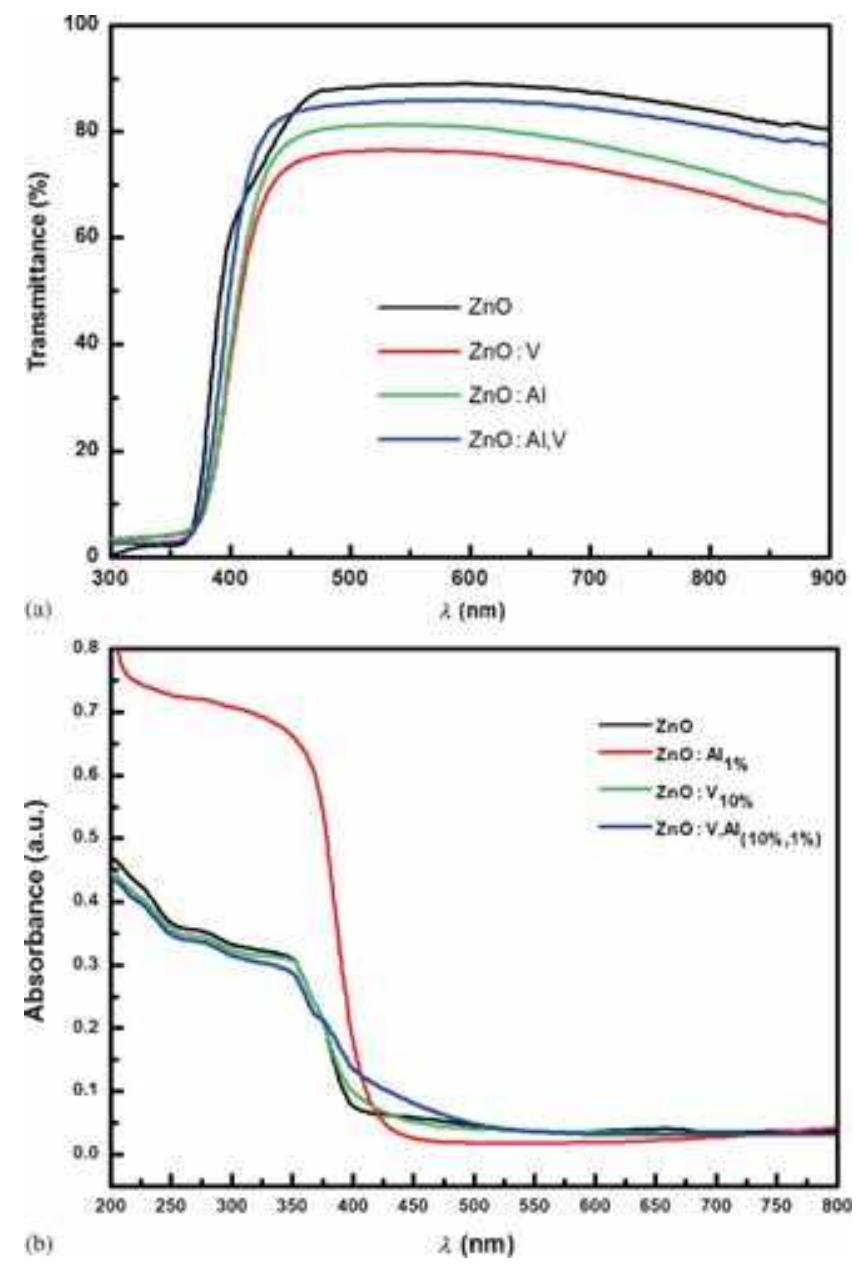

Figure 3. (a) Transmittance and (b) absorbance of $\mathrm{ZnO}, \mathrm{AlZ}, \mathrm{VZ}$ and AlVZ nanoparticles.

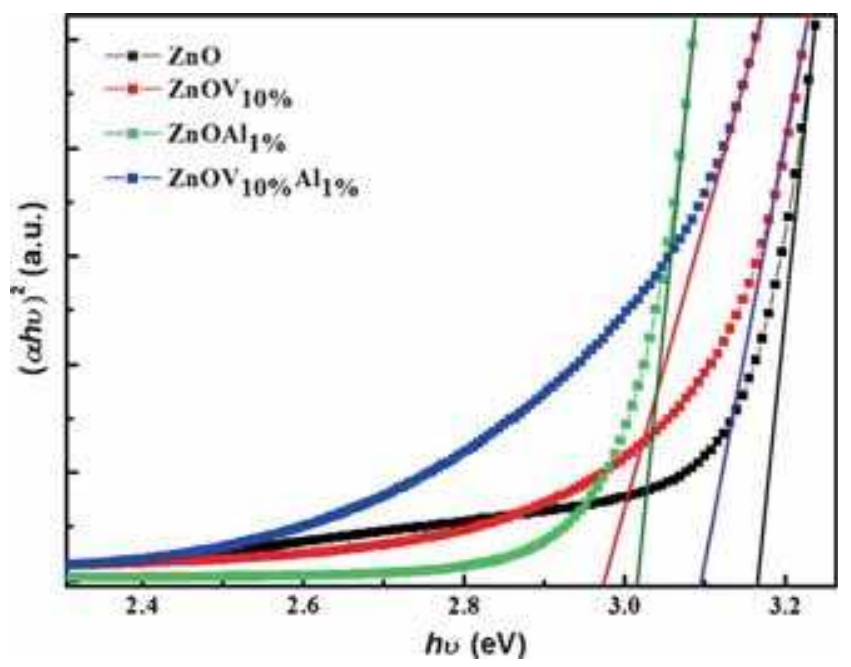

Figure 4. Plot $(\alpha h v)^{2} v s$. photon energy $(h v)$.

AlVZ shows that they are suitable for implementation as transparent contacts in various optoelectronic devices.

The PL study was carried out for evaluate the quality and evolution of the emission for two different wavelengths
Table 1. Electrical properties of all samples.

\begin{tabular}{lccc}
\hline Sample & $R_{\mathrm{S}}(\Omega)$ & $\rho(\Omega \mathrm{cm})$ & $T(\%)$ \\
\hline $\mathrm{ZnO}$ & 144 & $5.8 \times 10^{-3}$ & 89 \\
$\mathrm{VZ}$ & 210 & $8.1 \times 10^{-3}$ & 78 \\
$\mathrm{AlZ}$ & 182 & $7.2 \times 10^{-3}$ & 81 \\
$\mathrm{AlVZ}$ & 164 & $6.7 \times 10^{-3}$ & 86 \\
\hline
\end{tabular}

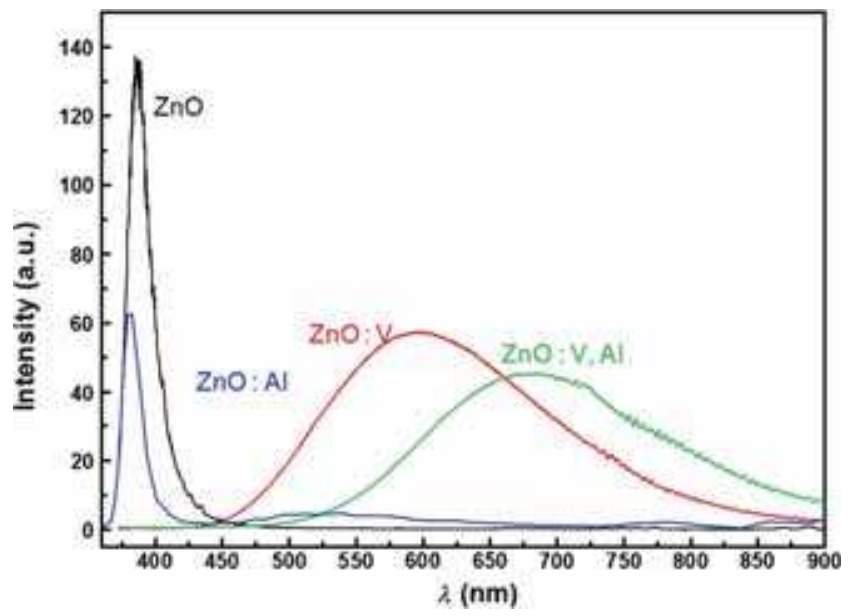

Figure 5. PL spectra of $\mathrm{ZnO}, \mathrm{AlZ}, \mathrm{VZ}$, and $\mathrm{AlVZ}$ nanoparticles at $78 \mathrm{~K}$.

depending on the temperature of measurement. Figure 5 shows the PL spectra of the all samples after heat treatment in an oven for $2 \mathrm{~h}$ at $500^{\circ} \mathrm{C}$ in air excited by $371 \mathrm{~nm}$ at room temperature. The undoped $\mathrm{ZnO}$ annealed in air exhibit a strong ultraviolet emission peak at $380 \mathrm{~nm}$, which corresponds to the near band edge peak that is responsible for the recombination of free $\mathrm{ZnO}$ excitons [29]. Generally, the intensity ratio between the ultraviolet emission band and the deep-level emission band is regarded as an indicator of the crystallinity of $\mathrm{ZnO}$ materials. In the case of $\mathrm{ZnO}$ doped, the PL spectra consist of a broad emission band located in the visible range of the green-yellow-red. It was shown from the works that the luminescence band in the case of metal transition (MT) elements doped $\mathrm{ZnO}$ is attributed to the effects of doping [2,24,30]. Other emissions in visible range were observed but the centers responsible of these emission bands and the related recombination mechanisms are not still understood and call further investigations.

The origins of the emission bands in $\mathrm{ZnO}$, are yet highly controversial and many attributions have been proposed [31-33]. Generally, $\mathrm{ZnO}$ exhibits two visible bands centred at 510-540 nm (green emission) and 600-640 nm (yellow emission), attributed to oxygen vacancy $\left(\mathrm{V}_{\mathrm{O}}^{+}\right)$[29], and oxygen interstitial $\left(\mathrm{O}_{\mathrm{i}}^{-}\right)$[32], respectively. Jin et al [31] reported a violet emission at $420 \mathrm{~nm}$ and attributed it to a transition between radiative defects level and the valence band. These radiative defects are related to the interface traps existing at the grain. Jeong et al [32] believed that the $\mathrm{Zn}$ vacancies $\mathrm{V}_{\mathrm{Zn}}$ 
are responsible for the violet emission at $401 \mathrm{~nm}$ wavelength. Fu et al [33] found a violet emission located at $392 \mathrm{~nm}$ in $\mathrm{ZnO}$ films on silicon substrate, they thought that this emission originated from the electron transition from the conduction band to the valence band. It has been suggested that the green emission is associated to oxygen deficiency, while the orange-red emission is associated to oxygen excess [34].

Figure 6 illustrates the temperature dependence of PL spectra of the AlVZ nanopowder. A blue shift and a reduction of PL intensity with decreasing temperature was observed. To the best of our knowledge, this blue shift behaviour of this emission band with temperature measurement had never been reported. The nature of the centres responsible of this emission band and the related recombination mechanisms are not still understood and call for further investigations. But it was concluded that doping $\mathrm{ZnO}$ with $\mathrm{Al}$ leads to green emission [35], while V-doping causes yellow emission [4,5]. One suggested that emission located to about $670 \mathrm{~nm}$ is in report with the competition between $\mathrm{V}_{\mathrm{O}}^{+}$and $\mathrm{O}_{\mathrm{i}}^{-}$. When impurity $\mathrm{Al}$ or $\mathrm{V}$ replaces $\mathrm{Zn}$ in the lattice, excess oxygen will be introduced as interstitial oxygen due to charge equilibrium [24].

To understand the emission mechanism in the sample, the respective variations of the integrated intensity of the peak as a function of 1000/T are plotted in the inset of figure 6 . The continuous curve represents the fit of the experimental points with the expression given by [36]. The best fit for our band luminescence is obtained for an activation energy $E_{\mathrm{a}}=56 \mathrm{meV}$.

In order to obtain further information about the recombination mechanisms responsible of the emission bands around 550 and 640, photoluminescence excitation (PLE) measurements were performed and presented in figure 7. These wavelengths were chosen in order to analyse the different

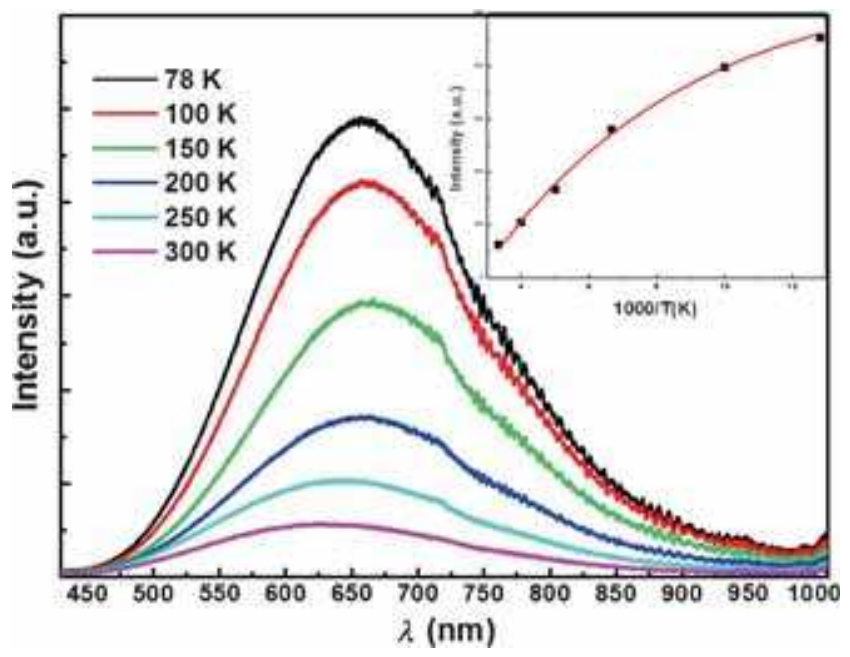

Figure 6. PL spectra of AlVZ at different temperature measurements. The inset showing the integrated intensity as a function of $1000 / T$. emissions. In fact, for the emission at $600 \mathrm{~nm}$, the wavelength of analysis at $550 \mathrm{~nm}$ corresponding to the short wavelength limit was studied and for the emission at $670 \mathrm{~nm}$ the wavelength of analysis at $640 \mathrm{~nm}$ was studied in order to see the contribution of the different centres of emission in this region. The PLE spectrum relative to defect emission presents a strong band at $371 \mathrm{~nm}$ observed at $78 \mathrm{~K}$, this position proves the contribution of $\mathrm{ZnO}$ nanoparticles.

The PL decay curve of AlVZ nanoparticles at $300 \mathrm{~K}$ is shown in figure 8 . The curve presents a bi-exponential decay, indicating that the lifetimes of $\mathrm{Mn}^{2+}$-excited states are composed of two components. Decay times may be obtained according the following equation [37]:

$$
I=B_{1} \mathrm{e}^{\left(-t / \tau_{1}\right)}+B_{2} \mathrm{e}^{\left(-t / \tau_{2}\right)},
$$

where $I$ is the luminescence intensity, $B_{1}, B_{2}$ the constants, $t$ the time, and $\tau_{1}, \tau_{2}$ the decay times. After fitting (blue line), a fast component is $2.3 \mathrm{~ns}$ and a slow component is $10 \mathrm{~ns}$ were obtained. It is clear that $\tau_{1}$ and $\tau_{2}$ are low, this result

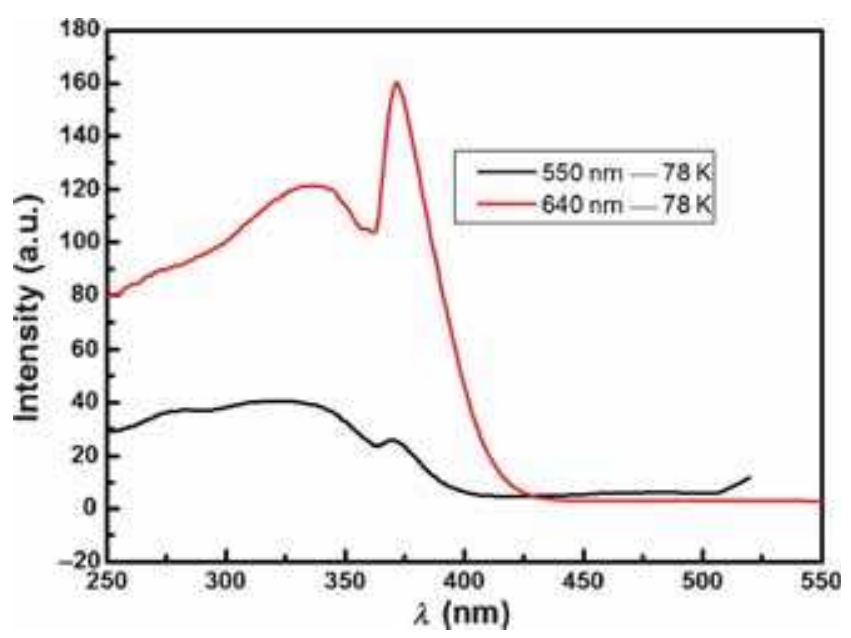

Figure 7. PLE spectra of AlVZ detected at 550 and $640 \mathrm{~nm}$.

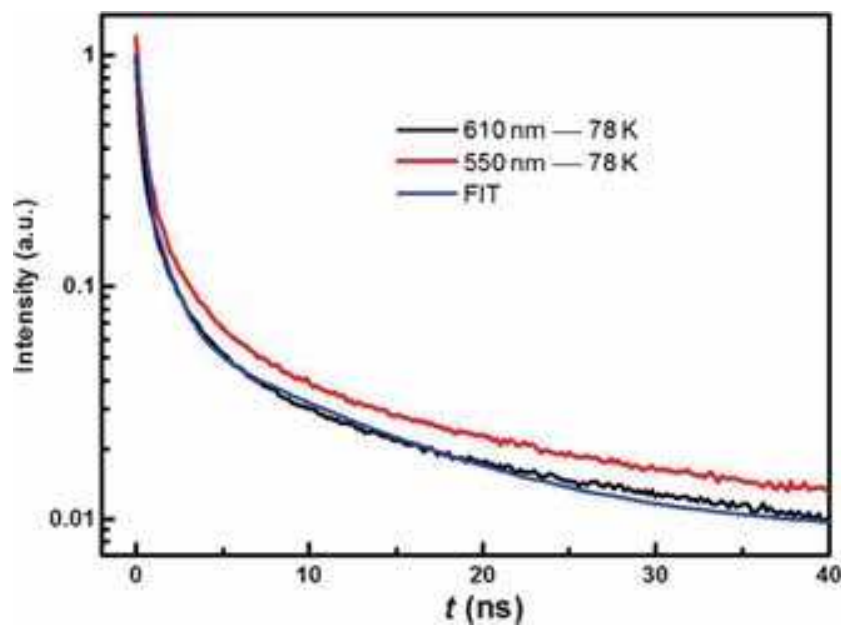

Figure 8. Decay curves of the AlVZ detected at 550 and $610 \mathrm{~nm}$. 
can be attributed to the increase in non-radiative recombination due to reduction in grain sizes and the decrease in radiative recombination due to suppression of defects after doping with $\mathrm{V}$ and $\mathrm{Al}$.

\section{Conclusion}

$\mathrm{Zn}_{0.89} \mathrm{~V}_{0.1} \mathrm{Al}_{0.01} \mathrm{O}$ nanoparticles were synthesized by the solgel method. The protocol of elaboration is based on slow hydrolysis of the precursor using an esterification reaction, followed by a supercritical drying in EtOH. The XRD and TEM analyses indicated the presence of nanocrystallites aggregated in different shape particles. The band gap decreases in the case of the doped $\mathrm{ZnO}$ samples. Regarding the doped samples, the highest average visible transmittance of $89 \%$ and the lowest resistivity of $6.7 \times 10^{-3} \Omega \mathrm{cm}$. PL spectra of the nanopowder showed strong yellow-red luminescence band. From the analysis of the PL and PLE spectra, it can be concluded that the contents of defect complexes involved by oxygen excess which introduced as interstitial oxygen due to charge equilibrium, associated with the presence of dopants in the powder was responsible of this luminescence band. These results provide some useful references for the potential application of the samples in optoelectronic devices.

\section{References}

[1] Kim Y M, Yoon M, Park I W, Park Y J and Lyou J H 2004 J. Solid State Commun. 129175

[2] El Mir L, El Ghoul J, Alaya S, Ben Salem M, Barthou C and von Bardeleben H J 2008 J. Phys. B: Condens. Matter 403 1770

[3] El Mir L, Ben Ayadi Z, Saadoun M, Djessas K, von Bardeleben H J and Alaya S 2007 J. Appl. Surf. Sci. 254 570

[4] El Ghoul J, Barthou C and El Mir L 2012 Physica E 441910

[5] El Ghoul J, Barthou C and El Mir L 2012 J. Superlattices Microstruct. $\mathbf{5 1} 942$

[6] El Ghoul J, Barthou C, Saadoun M and El Mir L 2010 J. Phys. B 405597

[7] Karmakar D, Mandal S K, Kadam R M, Paulose P L, Rajarajan A K, Nath T K, Das A K, Dasgupta I and Das G P 2007 J. Phys. Rev. B 75144404

[8] Khorsand Zak A, Abd. Majid W H, Abrishami M E, Yousefi R and Parvizi R 2012 J. Solid State Sci. 14488

[9] Nunes P, Fortunadeo E and Martins R 2001 Thin Solid Films 383277

[10] Jin B J, Im S and Lee S Y 2000 Thin Solid Films 366107

[11] Vanheusden K, Warren W L, Seager C H, Tallant D R, Voigt J A and Gnade B E 1996 J. Appl. Phys. 797983
[12] Greene L E, Law M, Goldberger J, Kim F, Johnson J C, Zhang Y, Saykally R J and Yang P 2003 Angew. Chem. Int. Ed. 42 3031

[13] Heo Y W, Norton D P and Pearton S J 2005 J. Appl. Phys. 981

[14] Studenikin S A, Golego N and Cocivera M 1998 J. Appl. Phys. 842287

[15] Liu X, Wu X, Cao H and Chang R P H 2004 J. Appl. Phys. 95 3141

[16] Wang M, Kim E J, Chung J S, Shin E W, Hahn S H, Lee K E and Park C 2006 Phys. Status Solidi A 2032418

[17] Li L J, Deng H, Dai L P, Chen J J, Yuan Q L and Li Y 2008 Mater. Res. Bull. 431456

[18] Fujihara S, Ogawa Y and Kasai A 2004 Chem. Mater. 162965

[19] Lee J Y, Jang B R, Lee J H, Kim H S, Cho H K, Moon J Y, Lee W J and Baek J W 2009 Thin Solid Films 5174086

[20] Gong Y, Andelman T, Neumark G F, O'Brien S and Kuskovsky I L 2007 Nanoscale Res. Lett. 2297

[21] Ohashi N, Ebisawa N, Sekiguchi T, Sakaguchi I, Wada Y, Takenaka T and Haneda H 2005 Appl. Phys. Lett. 861

[22] Nayak J, Kimura S, Nozaki S, Ono H and Uchida K 2007 Superlattices Microstruct. 42438

[23] El Mir L, Ben Ayadi Z, Saadoun M, von Bardeleben H J, Djessas K and Zeinert A 2007 Phys. Status Solidi (a) 204 3266

[24] El Mir L, Ghribi F, Ben Ayadi Z, Djessas K, Cubukcu M and von Bardeleben H J 2011 Thin Solid Films 5195787

[25] Wang L, Meng L, Teixeira V, Song S, Xu Z and Xu X 2009 Thin Solid Films $\mathbf{5 1 7} 3721$

[26] El Ghoul J, Bouguila N, Gómez-Lopera S A and El Mir L 2013 Superlattices Microstruct. 64451

[27] Cogan S F, Nguyen N M, Perrotti S J and Rauh R D 1989 J. Appl. Phys. 661333

[28] Zhong Z Y and Zhang T 2013 Mater. Lett. 96237

[29] Kong Y C, Yu D P, Zhang B et al 2001 Appl. Phys. Lett. 78 407

[30] El Ghoul J, Barthou C, Saadoun M and El Mir L 2010 Physica B 405597

[31] Jin B J, Im S and Lee S Y 2000 Thin Solid Films 366107

[32] Jeong S H, Kim B S and Lee B T 2003 Appl. Phys. Lett. 82 2625

[33] Fu Z X, Guo C X, Lin B X and Liao G H 1998 Chim. Phys. Lett. 15457

[34] Teke A, Ozgur U, Dogan S, Gu X, Morkoç H, Nemeth B, Mause J and Everitt H O 2004 Phys. Rev. B 70 195207

[35] Wang M, Lee K E, Hahn S H, Kim E J, Kim S, Chung J S, Shin E W and Park C 2007 Mater. Lett. 611118

[36] Leroux M, Grandjean N, Beaumont B, Nataf G, Semond F, Massies J and Gibart P 1999 J. Appl. Phys. 863721

[37] Wang Y, Hao Y and Yuwen L 2006 J. Alloys Compd. 425 339 